\title{
Behavioral assessment of sodium arsanilate induced vestibular dysfunction in rats
}

\author{
KRIS M. HORN, JOHN R. DeWITT, and HAROLD C. NIELSON \\ University of Utah, Salt Lake City, Utah 84112
}

\begin{abstract}
Vestibular dysfunction was induced in Long-Evans and Wistar rats-previously thought to be refractory to the effects of ototoxic drugs-by subcutaneous or intratympanic injections of sodium arsanilate (atoxyl). Three measures of swimming behavior were taken to assess the degree of vestibular dysfunction. These measures were: escape latencies, errors, and underwater swimming times. Subcutaneous injections of sodium arsanilate that resulted in no behavioral impairment of previously trained rats resulted in less efficient learning of the maze by naive rats. Visual compensation for vestibular impairment was detected by altering or removing the visual cues the rats used in their compensation. A strain difference in sensitivity to subcutaneous injections of sodium arsanilate was found between the Wistar and Long-Evans rats, with the Wistar rats being much more sensitive.
\end{abstract}

In primitive animals, the vestibular system evolved to provide information about body orientation. Then, as higher animal forms evolved and the head was connected to the body by a neck, the vestibular system provided information about the orientation of the head. Information about the orientation of the body then resulted from the convergence of information from the visual and proprioceptive systems with the vestibular system. The neck and vestibular systems appear to cooperate to provide a stable visual image, while equilibrium, or maintenance of balance, appears to be an integration of all these systems with the motor system (Howard \& Templeton, 1968). Higher organisms use input from all of these systems to orient themselves in space (Parker, 1980), with most being able to tolerate the removal of one of these sensory modalities and still maintain adequate orientation as long as they are not stressed or required to perform complex tasks (Hawkins \& Preston, 1975). The ability to maintain body orientation with one of these systems absent was seen in the early clinical studies with streptomycin, an ototoxic antibiotic (Glorig \& Fowler, 1947; Northington, 1950). Patients receiving large daily doses of streptomycin initially reported problems of equilibrium and difficulty in focusing their eyes on objects, with the objects under visual focus appearing to jump. While these symptoms subsided within a few weeks, problems with maintaining equilibrium would reappear when the patients were in the dark. These problems were subsequently identified as vestibular in origin.

Supported by NASA Grant NSG-2350 to H. C. Nielson. The authors wish to express their appreciation to Abbott Laboratories for supplying Pro Gen W (sodium arsanilate). The research described in this article adhered to the Guide for Laboratory Animal Facilities and Care. Reprint requests should be addressed to Kris M. Horn, Department of Psychology, University of Utah, Salt Lake City, Utah 84112.
The reasons for not observing these difficulties in the rats and mice upon which streptomycin was first tested is not apparent. Molitor, Graessle, Kuna, Mushett, and Silber (1946) stated that the only animal that shows a toxic effect of streptomycin comparable to that seen in man is the dog. They specifically excluded the frog, mouse, rat, and guinea pig as being susceptible to streptomycin. However, a number of ototoxic drugs have now been identified, and a behavioral test of vestibular functioning would be useful for drug screening as well as for behavioral evaluations of processes of sensory integration. In addition, many of the ototoxic drugs are routinely administered to research animals on a daily basis, and a simple test of possible vestibular dysfunction in the rat may prove useful.

The drugs that have been reported to be toxic to the inner ear structures including the vestibular apparatus include the aminoglycosidic-like antibiotics and arsenical compounds. Among those drugs that appear to be more toxic to the vestibular apparatus than to the cochlea are streptomycin (Duvall \& Wersall, 1964), neomycin (Hawkins \& Lurie, 1953), viomycin (Kanda \& Igarashi, 1969), gentamicin (Hawkins, Johnsson, \& Aran, 1969), arsacetin (Johansen, 1953), and sodium arsanilate (atoxyl) (Anniko \& Wersall, 1977). These drugs appear to damage mainly the peripheral vestibular end organ, particularly the secretory epithelium of the crista, macula, and the types I and II sensory hair cells. Specifically, Lindquist (1973) and Hawkins and Preston (1975) have suggested that destruction of the marginal secretory cells of the crista and macula, which are associated with melanin-containing melanocytes, leads to a disruption of the osmolarity of the system, and that leads to a secondary destruction of types I and II hair cells. Contrary to the report of Molitor et al. (1946), many species besides man and 
dog are reported to be sensitive to these ototoxic drugs. These species include pigs, pigeons, and mice (Hawkins \& Preston, 1975; Anniko \& Wersall, 1977; Causse, Gendet, \& Vallancian, 1948). Rats are not frequently used in investigations of vestibular functions and appear to be refractory to the systemic action of streptomycin (Riccio, Igarashi, \& Eskin, 1967). The supposed refractoriness of rats to these drugs may be due to a highly resilient vestibular system, to an excretory system that rapidly eliminates ototoxic drugs, or to the lack of a sensitive behavioral measure to assess vestibular dysfunction.

Typical tests to assess vestibular integrity in species other than rats include changes in the interaction of the hand and eyes in lateral gaze shifts (Dichgans, Bizzi, Morasso, \& Tagliasco, 1973), changes in postrotational nystagmus (Jongkes \& Hulk, 1950), increase in incidence of ataxia (Hawkins et al., 1969), loss or delay of righting reflex (Watt, 1976), balance on a rotating rail (Igarashi, 1968), spontaneous activity levels during lateral rotation (Riccio et al., 1967), and morphological examination of the labyrinth (Anniko \& Wersall, 1975). There have been a few reports of swimming being used to assess vestibular integrity. These include swimming by infant monkeys following streptomycin intoxication or exposure to manganese-deficient diets (Riolpella \& Hubbard, 1979), by toads following labyrinthectomies (Gray \& Lissman, 1947), by rats following unilateral or bilateral labyrinthectomies (T'ang \& Wu, 1936, 1937), by tadpoles following labyrinthectomies and blinding (Horn \& Rayer, 1978), and by mice following streptomycin injections (Causse et al., 1948). These swimming tests appear only to have determined the organisms' ability to find or remain on the surface of the water without engaging in other goal-directed behavior. Since body orientation is a function of the integration of proprioceptive, visual, and vestibular systems with the motor system, it would appear that restriction or elimination of sensory input from some of these sensory systems may offer a behavioral means of evaluating the integration of the systems involved in body orientation. For this reason, swimming behavior holds promise as a sensitive index of the degree of vestibular disruption. With the rat swimming or floating toward an escape ladder, the effectiveness of proprioceptive cues will be reduced and will increase the animal's reliance upon vestibular and visual stimulation for its orientation. Visual and vestibular sensory input can be altered, vestibular input by the administration of ototoxic drugs and visual input by changing locations of light sources or eliminating light altogether. With such alterations in sensory inputs, it should be possible to evaluate the contributions of each of these sensory systems to the rat's swimming performance. In addition, small degrees of vestibular dysfunction that are not normally detected by other swimming tests may be identified.

\section{GENERAL METHOD}

\section{Apparatus}

The configuration of the water maze used in these experiments is shown in Figure 1. It was constructed of clear glass that was $.7 \mathrm{~cm}$ thick with sides $1 \mathrm{~m} \times 60 \mathrm{~cm}$ and a $1 \times 1 \mathrm{~m}$ bottom. The alleys, located at the corners of the maze at a 45-deg angle to the side of the maze, were $35 \mathrm{~cm}$ long and $12.5 \mathrm{~cm}$ wide. The edges were reinforced with $1.8-\mathrm{cm}$ angle iron that was painted flat black. Heavy black drapes were occasionally used to cover various parts of the maze to provide changeable extramaze cues. Illumination was provided by a $4-\mathrm{W}$ light suspended $1 \mathrm{~m}$ above the center of the maze.

\section{Procedure}

All rats were housed individually and maintained with ad-lib access to food and water throughout the experiments. Five daily training trials were given for 7 days to allow the rats to learn to swim directly from the starting alley to the escape ladder located in the diagonally opposite alley. The positions of the starting alley and the escape ladder were kept constant throughout the course of the experiments. Water in the maze was $38 \mathrm{~cm}$ deep and was kept at $13^{\circ} \mathrm{C}$ to facilitate optimum escape conditions (Pusakulich $\&$ Nielson, 1976). Between trials, the rats were placed in a square metal tub heated with a lamp. Four items were recorded on each trial: the latency to swim from the start alley to the escape ladder, total underwater swimming time, errors (whenever the rat entered an alley other than the one with the escape ladder), and the approximate path taken. Percentage of underwater time for each trial was computed by dividing the amount of time underwater for the trial by the total amount of time taken to swim the maze in that trial.

Swimming times in seconds were converted to $\log _{10}$, and errors and percentage of time underwater were converted into $\log _{10}(x+1)$ to reduce correlations between the means and variances.

\section{EXPERIMENT 1}

Subcutaneous injections of sodium arsanilate (atoxyl) have been reported to be toxic to the ves-

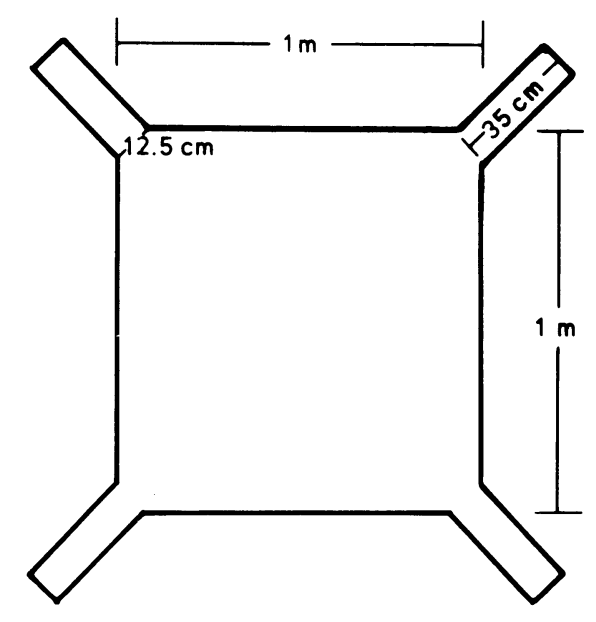

Figure 1. Configuration of the water maze as viewed from above. The water maze has clear glass sides that are $1 \mathrm{~m}$ long, $60 \mathrm{~cm}$ high, and $.7 \mathrm{~cm}$ thick. The bottom, also of clear glass, is $1 \mathrm{~m}$ square. The arms at the corners of the maze are $35 \mathrm{~cm} l o n g, 60 \mathrm{~cm}$ high, and $.6 \mathrm{~cm}$ thick. The width of the arms is $12.5 \mathrm{~cm}$. 
tibular system in species such as guinea pigs (Anniko \& Wersall, 1975, 1976, 1977), but little research has been attempted utilizing rats. The purpose of this first experiment was to determine the effects of subcutaneous injections of sodium arsanilate on the swimming behavior of two strains of rats, Wistar and Long-Evans.

\section{Method}

Subjects. The subjects were 6 male Long-Evans (Blue-Spruce Farms) and 12 male Wistar (6 from Blue-Spruce, 6 from the Psychology Department colony) rats that weighed between 330 and $375 \mathrm{~g}$ at the beginning of the experiment.

Procedure. After the seven daily training sessions, performances were stable. Six hours prior to the eighth session, all rats received their first $40-\mathrm{mg} / \mathrm{kg}(20 \mathrm{mg} / \mathrm{ml}$, saline vehicle) subcutaneous injection of sodium arsanilate (Pro Gen W, Abbott Labs.) in the thoracic portion of the back. Previous pilot work utilizing sodium arsanilate had shown that $40-\mathrm{mg} / \mathrm{kg}$ subcutaneous injections rapidly induced vestibular dysfunction in Wistar rats without being lethal. Two additional injections of sodium arsanilate $(40 \mathrm{mg} / \mathrm{kg}, \mathrm{sc})$ preceded the 9th and 10th sessions, after which injections for the Wistar rats were discontinued because their escape responses were disrupted. When this occurred, only two daily trials were given with a 5-min rest period between trials. The six Long-Evans rats continued to receive daily injections of sodium arsanilate $(40 \mathrm{mg} / \mathrm{kg}, \mathrm{sc})$ for 7 days when the dose was then increased to $60 \mathrm{mg} / \mathrm{kg}$ (sc) for an additional 10 days, followed by 3 days of $80 \mathrm{mg} / \mathrm{kg}$ (sc). Sodium arsanilate injections were discontinued, but testing in the water maze continued for 36 days for the 12 Wistar rats and 16 days for the 6 Long-Evans rats.

\section{Results}

Two-way analysis of variance with repeated measures indicated that all three measures: swim times $[F(2,15)=6.512, p<.01]$, errors $[F(2,15)=7.267$, $\mathrm{p}<.01]$, and underwater time $[F(2,15)=6.672$, $p<.01$ ] were different for strain of animal. Additionally, effects across days were found for swim times $[F(39,520)=6.82, p<.001]$, errors $[F(39,520)$ $=5.29, \mathrm{p}<.001]$, and underwater time $[\mathrm{F}(39,520)$ $=6.83, \mathrm{p}<.001]$. Sodium arsanilate disrupted the swimming behavior of both Wistar and Long-Evans rats. However, not only were the individual daily doses to dysfunction different, but their total cumulative doses were greatly different $(120 \mathrm{mg} / \mathrm{kg}$ for the Wistars compared with $1,400 \mathrm{mg} / \mathrm{kg}$ for the LongEvans). In addition, the Long-Evans rats recovered from or compensated for the dysfunction, but the Wistars never did completely recover. The swim times for the two groups are shown in Figure 2.

\section{Discussion}

We first obtained the differences between the Wistar and Long-Evans rats in animals obtained from BlueSpruce Farms. Following this, we obtained and ran an additional six Wistars from our departmental colony, to verify the debilitating effects of sodium arsanilate on Wistar rats. This second group of six Wistars was run approximately 1 month after the animals obtained from Blue-Spruce Farms, and were

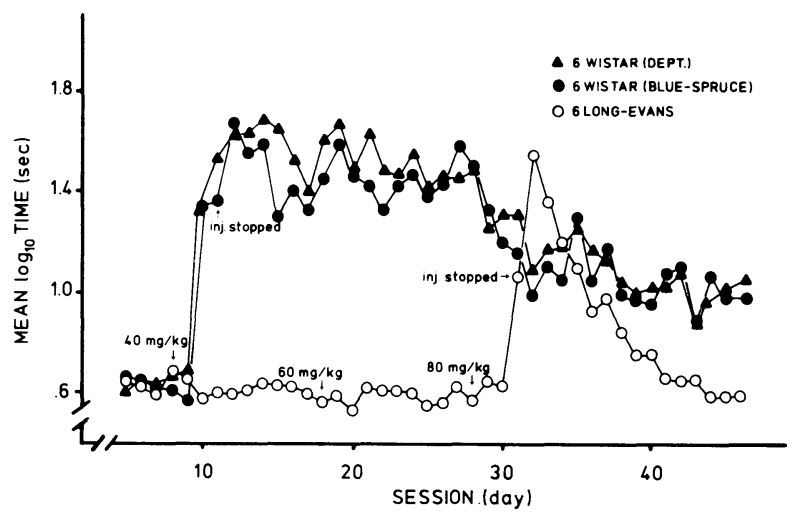

Figure 2. The mean $\log _{10}$ swimming times (seconds) in the water maze. The 12 Wistar (solid circles, Blue Spruce; solid triangles, Psychology Department) rats received daily doses of $\mathbf{4 0 ~} \mathrm{mg} / \mathrm{kg}$ for Sessions 8-10 and nothing thereafter. The six Long-Evans (open circles) rats received daily doses of $\mathbf{4 0} \mathrm{mg} / \mathrm{kg}$ for Sessions 8-17, $60 \mathrm{mg} / \mathrm{kg}$ for Sessions $18-27,80 \mathrm{mg} / \mathrm{kg}$ for Sessions $28-30$, and nothing thereafter.

treated and handled the same way in every respect. The results for the two groups of Wistars were the same. After three daily injections of $40 \mathrm{mg} / \mathrm{kg}$ of sodium arsanilate, the swimming behavior of all 12 of the Wistars was affected while none of the LongEvans were affected. Time differences in running the rats cannot explain these results. Such clear-cut differences cannot be attributed to handling or procedural differences because there were none. Because Anniko and Ljungqvist (1977) demonstrated that sodium arsanilate damages the secretory cells of the renal tubules, we suggest that the strain difference reported here results from differences in the way the kidneys of the two strains eliminate sodium arsanilate. We suggest that this strain difference results from the sodium arsanilate's producing damage to the renal tubules of the Wistars that interferes with its excretion. This, in turn, results in a prolonged retention of the drug in the circulatory system, which in turn exposes the vestibular apparatus of the Wistar rats to higher levels of the drug. We do not believe that the vestibular apparatus of the Wistars is more sensitive to sodium arsanilate than is the vestibular apparatus of the Long-Evans, because no strain differences in sensitivity to this drug were found with the intratympanic injections that were used in Experiment 2 .

\section{EXPERIMENT 2}

In order to produce graded vestibular dysfunction and to minimize side effects produced by large systemic doses of sodium arsanilate, a procedure similar to the one developed by Riccio et al. (1967) was used. A solution of sodium arsanilate was injected directly into the middle ear cavity through the tympanic membrane. In this way, the amount of the ototoxic drug 
could be varied to induce immediate graded levels of vestibular dysfunction, without side effects possibly due to long-term systemic injections.

\section{Method}

Subjects. The subjects were 18 male Long-Evans and 12 male Wistar rats, weighing 350-400 g at the onset of the experiment.

Procedures. After the initial seven daily training sessions in the water maze, the 30 rats were divided into six groups of five rats, each with three Long-Evans and two Wistar rats, and anesthetized with sodium pentobarbital $(40 \mathrm{mg} / \mathrm{kg}$, ip). The five rats in the control group received an injection of $.14 \mathrm{ml}$ normal saline into each middle ear cavity. The experimental rats received smaller volumes of injections. The rats that received the $1,2.5$, and $5 \mathrm{mg} / \mathrm{kg}$ sodium arsanilate received it in a normal saline vehicle $(20 \mathrm{mg} / \mathrm{ml})$ with volumes ranging from .02 to $.12 \mathrm{ml}$, while those that received 10 or $20 \mathrm{mg} / \mathrm{kg}$ sodium arsanilate received it in a dose utilizing a $100-\mathrm{mg} / \mathrm{ml}$ concentration of sodium arsanilate in normal saline with volumes ranging from .03 to $.10 \mathrm{ml}$. After each injection, the external auditory measures were packed with Gelfoam (Upjohn Co.). After the intratympanic injections, the rats were returned to their home cages to recover from anesthesia. Testing in the water maze began the following day. Test sessions were reduced to two trials each test day, with 15 min between trials to minimize fatigue within each session. All rats were tested on Days 1, 2, 6, $9,13,16,25,35$, and 45 following the intratympanic injections.

\section{Results}

No strain differences were found. Comparison of the performance measures between the Wistar and Long-Evans rats within each treatment group revealed no differences in sensitivity to sodium arsanilate through middle-ear injections.

The day following the intratympanic injections, all groups except the saline group had an increase of swimming times, errors, and percentage of time underwater. Performance measures are summarized in Figure 3. Swimming times of all groups except the control were increased within $24 \mathrm{~h}$, and all but the groups receiving the lower doses remained elevated

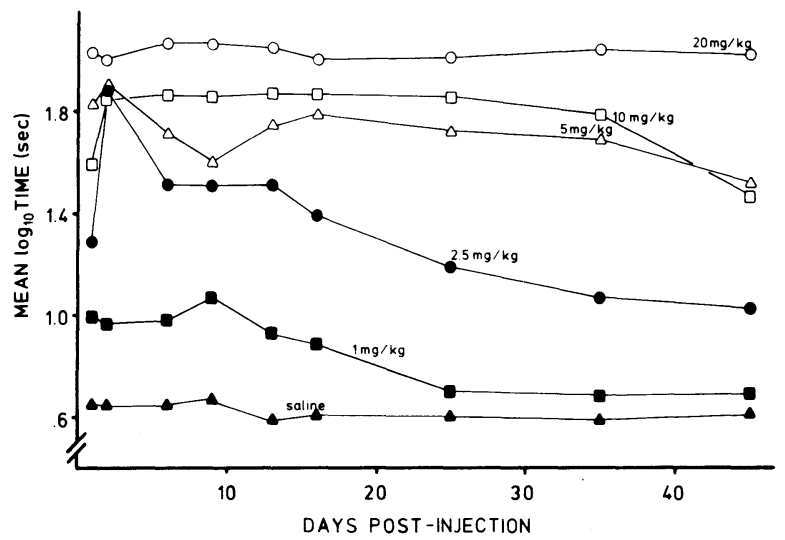

Figure 3. A comparison of the mean $\log _{10}$ swimming times (seconds) for 30 trained rats during a 45-day test period following a single bilateral intratympanic injection of sodium arsanilate. Rats received saline injections (solid triangles), $1 \mathrm{mg} / \mathrm{kg}$ (solid squares), $2.5 \mathrm{mg} / \mathrm{kg}$ (solid circles), $5 \mathrm{mg} / \mathrm{kg}$ (open triangles), $10 \mathrm{mg} / \mathrm{kg}$ (open squares), or $20 \mathrm{mg} / \mathbf{k g}$ (open circles). thereafter. A two-way analysis of variance with repeated measures revealed an effect due to the dose of drug $[F(5,54)=101.776, p<.001]$, to changes across days $[\mathrm{F}(5,54)=6.849, \mathrm{p}<.001]$, and to a dose $\times$ day interaction $[F(40,432)=1.59, p<.01]$. Simple main effects due to the doses of sodium arsanilate were all reliably different at the $\mathrm{p}<.001$ level for all 9 test days $[F s(5,200)=27.556,34.503,30.310,27.008$, $31.513,31.300,37.480$, and 30.036]. Similarly reliable effects were found for both of the other measures, errors and percentage of swimming time underwater.

Graded vestibular dysfunction was induced in rats by varying the dosage and concentration of sodium arsanilate injected into the middle-ear cavity. Temporary damage or damage that was quickly compensated for was induced with $1-\mathrm{mg} / \mathrm{kg}$ intratympanic injections with recovery in 16 days. More severe damage and a longer compensatory period of approximately 25 days were produced by the $2.5-\mathrm{mg} / \mathrm{kg}$ dose. Both 5- and $10-\mathrm{mg} / \mathrm{kg}$ injections produced long-lasting swimming deficits that showed only slight recovery during the 45-day test period. The greatest, and apparently permanent, deficits followed the 20$\mathrm{mg} / \mathrm{kg}$ injections. Severe disorientation and an inability to find and remain on the surface of the water was common in this group. The $20-\mathrm{mg} / \mathrm{kg}$ dose appeared to mimic the effects of bilateral labyrinthectomies (Gray \& Lissman, 1947; Igarashi, Watanabe, \& Maxian, 1970; T'ang \& Wu, 1937), and there was no recovery.

\section{Discussion}

The injection of physiological saline into the middle ear in larger volumes than those of the treatment groups did not appear to affect the escape behavior of the control group. Hence, it appears that the sodium arsanilate was responsible for inducing the swimming deficits, probably by inducing vestibular damage.

An advantage of the intratympanic method was that it induced vestibular dysfunction with only one injection and at low doses. The fact that the intratympanic injections produced the same effect at the same dose, regardless of strain, strongly suggests that the strain difference found in the first experiment was not due to differential sensitivity of the vestibular apparatus of the two strains. Thus, the strain differences may be due to systemic effects resulting from differential renal clearance times of sodium arsanilate between the Wistar and Long-Evans rats.

\section{EXPERIMENT 3}

Experience in the water maze may affect the degree to which vestibular dysfunction is manifested, because there may be some visual compensation. This possibility was investigated in this experiment. 


\section{Method}

Subjects and Procedure. Eight male Wistar rats that weighed between 400 and $450 \mathrm{~g}$ were divided into two groups of four. The experimental group received two subcutaneous injections of sodium arsanilate $(40 \mathrm{mg} / \mathrm{kg})$ spaced $24 \mathrm{~h}$ apart. The four rats in the control group received comparable volumes of normal saline (sc) at the same times as the experimental group.

The day following the second injection, both groups received their first session in the water maze, and testing continued for 5 consecutive days. Each rat received five trials each day in the water maze.

\section{Results}

The experimental group, treated with sodium arsanilate, had increased swimming times, errors, and percentages of time underwater as compared with the control group. Repeated-measures two-way analyses of variance revealed an effect due to drug administration for all three measures [swimming times, $\mathrm{F}(1,6)=$ $22.89, \mathrm{p}<.01$; errors, $\mathrm{F}(1,6)=101.4, \mathrm{p}<.01$; and percentage of time underwater, $F(1,6)=27.887$, $\mathrm{p}<.01$ ]. Figures 4, 5, and 6 illustrate the swimming

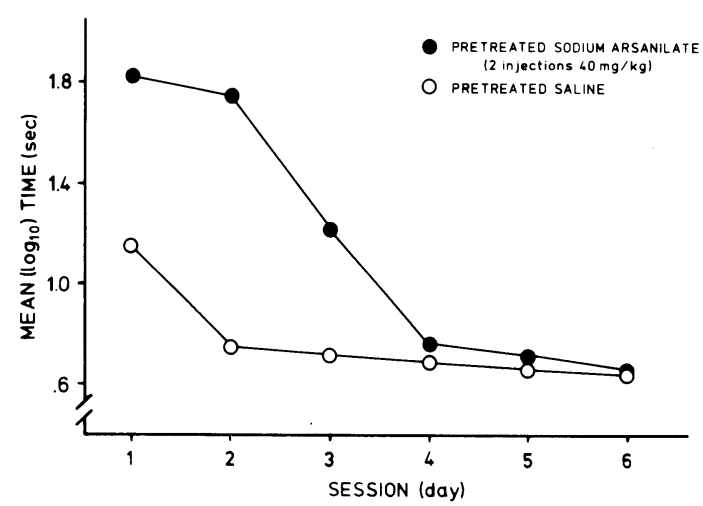

Figure 4. A comparison of mean $\log _{10}$ swimming times (seconds) during the first six sessions of training in the water maze by four saline-injected (sc) Wistar rats (open circles) and four Wistar rats (solid circles) pretreated with two injections of sodium arsanilate (40 mg/kg, sc).

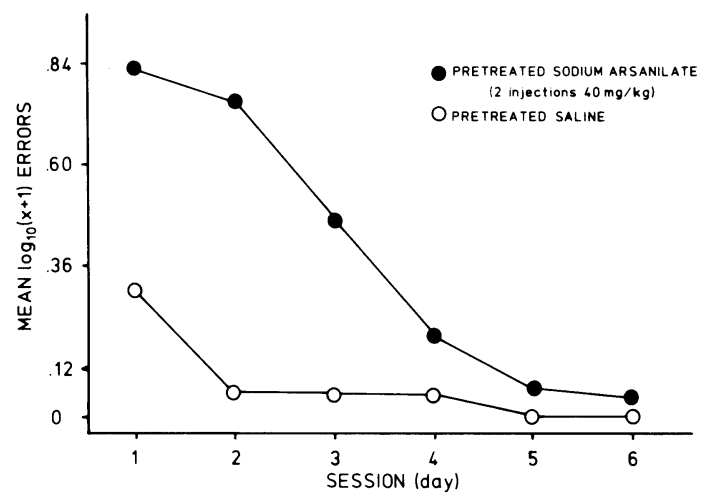

Figure 5. A comparison of the mean $\log _{10}(x+1)$ errors during the first six sessions of training in the water maze by four salineinjected (sc) Wistar rats (open circles) and four Wistar rats (solid circles) pretreated with two injections of sodium arsanilate $(40 \mathrm{mg}$ / kg, sc).

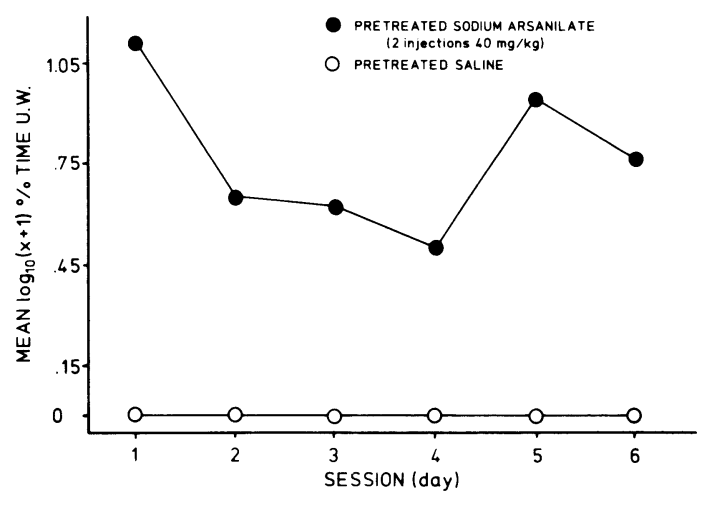

Figure 6. A comparison of the mean $\log _{10}(x+1)$ percentage of time spent underwater during the first six sessions of training in the water maze by four saline-injected (sc) Wistar rats (open circles) and four Wistar rats (solid circles) pretreated with two injections of sodium arsanilate $(40 \mathrm{mg} / \mathrm{kg}$; sc).

times, errors, and percentage of time underwater, respectively. Significant changes occurred across days for the swimming times $[\mathrm{F}(5,30)=25.52, \mathrm{p}<.01]$ and errors $[F(5,30)=22.333, p<.01]$, but not percentage of time underwater. Analysis of simple main effects for individual sessions between groups for swimming times showed that the differences between the control group and the injection group were found on the first three sessions $[\mathrm{F}(1,30)=22.613,38.647$, $12.475, \mathrm{p}<.01]$. Errors were also different for the first three sessions $[F(1,30)=35.59,60.692,21.35$, $p<.01]$. The percentages of time spent underwater were different between the two groups [Session 1, $F(1,30)=19.761, p<.01$; Session $2, F(1,30)=6.279$, $\mathrm{p}<.05$; Session 5, $\mathrm{F}(1,30)=14.762, \mathrm{p}<.01$; and Session $6, F(1,30)=9.465, p<.01]$.

\section{Discussion}

While we cannot rule out the possibility that these results reflect a generalized illness produced by the sodium arsanilate, there was no evidence that the rats were distressed. There were no drops in body weight to suggest that food had not been eaten. Furthermore, after 4 days, the latencies and errors of the two groups were not different; what was different was the swimming styles of the two groups. Throughout all six sessions, the experimental rats continued to swim parts of the maze submerged, perhaps reflecting a difference in how the two groups learned to escape from the water. Finally, the rats in the first experiment that also received two subcutaneous injections of $40 \mathrm{mg} / \mathrm{kg}$ sodium arsanilate did not have slower swimming latencies until after the third injection. For these reasons, then-no disruption of eating, no changes in swimming latencies in experienced swimmers, and a different swimming style with more underwater swimming-we believe these results reflect swimming experience and vestibular functioning rather than a generalized illness. 


\section{EXPERIMENT 4}

Clinical studies (Fregly \& Graybiel, 1970; Glorig \& Fowler, 1947) have demonstrated that persons with bilateral vestibular dysfunction are normally able to maintain their equilibrium as long as their vision is not occluded. However, once visual cues are removed, they typically are unable to maintain their balance. This was originally demonstrated with persons receiving streptomycin treatments (Glorig \& Fowler, 1947; Northington, 1950) for tuberculosis. Hawkins and Preston (1975) indicated that compensation was achieved through increased reliance upon visual and proprioceptive cues, and that walking in the dark presented special difficulties, even after other equilibrium problems had subsided.

Experiment 2 indicated that rats with smaller doses of sodium arsanilate $(1$ and $2.5 \mathrm{mg} / \mathrm{kg}$ ) recover swimming efficiency. This may indicate either a recovery of vestibular function or visual compensation for any vestibular impairment that remained. If visual compensation had occurred, it would be likely that the rats would come to show a greater reliance upon visual cues to help maintain a dynamic equilibrium in the water. In this experiment we investigated the effects of visual stimuli by introducing visual cues that were incongruous with the cues the rats had previously encountered in the maze or by eliminating visual cues by having the rats swim in the dark.

\section{Method}

Subjects. Eight rats from Experiment 2, five Long-Evans and three Wistar, that had regained their water maze performance following injections of sodium arsanilate served as experimental subjects. Eight additional rats, five Long-Evans and three Wistar, served as controls.

Apparatus. The water maze was again utilized in the same physical conformation as in the previous experiments. Light conditions were varied by placing the $4-\mathrm{W}$, partially shielded light at two positions other than directly overhead. The light was placed $1 \mathrm{~m}$ below the bottom of the maze with the black drapes over the top of the maze and the right side of the start alley, or the light was placed $1 \mathrm{~m}$ from the center of a side of the maze adjacent to the start alley and the top and right side of the start alley were draped. The rats were also tested under dim red illumination.

Procedures. The experimental group was selected from among those rats used in Experiment 2 that had recovered swimming performance. The criteria for selection were: (1) no errors were made in the last three sessions; (2) no underwater swimming occurred in the three previous sessions; and (3) each rat had an average swimming time of less than $10 \mathrm{sec}$ for the three previous sessions. Five rats from the $1-\mathrm{mg} / \mathrm{kg}$ group and three rats from the $2.5-\mathrm{mg} / \mathrm{kg}$ group were selected for this study.

A control group composed of the same ratio of Wistar to LongEvans rats were selected and received the same number of total trials in the water maze.

All rats were then tested under three conditions of altered lighting: (1) total darkness; (2) light source from beneath the maze; and (3) light source from the side of the maze. Order of presentation of the three conditions was randomized. The rats received two trials in each condition and only one lighting condition per day, with the other two conditions being presented on successive days.

\section{Results}

The alterations of lighting affected the "recovered" rats more than the controls. The mean swimming times, errors, and percentage of time underwater are presented in Table 1. Repeated-measures two-way analyses of variance indicated that the two groups differed in their swimming times $[\mathrm{F}(1,30)=19.909$, $\mathrm{p}<.01]$, errors $[\mathrm{F}(1,30)=13.182, \mathrm{p}<.01]$, and percentage of underwater time $[\mathrm{F}(1,30)=6.665, \mathrm{p}<$ $.01]$. Analysis of simple main effects indicated that the experimental group differed from the control group in the swimming times for the bottom illumination $[F(1,120)=12.235, p<.01]$ and the dark condition $[F(1,120)=24.837, p<.01]$. Simple main effects for errors between the two groups in the four conditions indicated differences for bottom lighting $[F(1,120)=10.194, p<.01]$ and for the dark $[F(1$, $120)=16.373, p<.01]$. All three variations of lighting showed effects for percentage of time underwater [side, $\mathrm{F}(1,120)=8.517, \mathrm{p}<.01$; bottom, $\mathrm{F}(1,120)=$ $6.150, \mathrm{p}<.05$; and dark, $\mathrm{F}(1,120)=7.54, \mathrm{p}<.01$ ]. Due to the selection factors for inclusion in the study, there were no significant differences between the experimental and control groups in the initial overhead illumination condition.

\section{Discussion}

Vestibular dysfunction can be compensated for visually, but it is not observed except under altered lighting conditions. The rats that had recovered swimming proficiency when swimming in the light became erratic swimmers, compared with normal animals and their own swimming performance, when lighting

Table 1

Mean Performance on Three Measures for Normal (N) and Compensated (C) Rats Under Altered Lighting Conditions

\begin{tabular}{|c|c|c|c|c|c|c|}
\hline \multirow[b]{3}{*}{ Lighting } & \multicolumn{6}{|c|}{ Measure } \\
\hline & \multicolumn{2}{|c|}{ Swim Time $\log _{1}$ 。(in Seconds) } & \multicolumn{2}{|c|}{ Errors $\log _{10}(x+1)$} & \multicolumn{2}{|c|}{ Percent Underwater $\log _{10}(x+1)$} \\
\hline & $\mathrm{N}$ & $\mathrm{C}$ & $\mathbf{N}$ & $\mathrm{C}$ & $\mathrm{N}$ & $\mathrm{C}$ \\
\hline Above (Normal) & .6952 & .7650 & 0 & 0 & 0 & 0 \\
\hline Side & .7685 & .9077 & .0188 & .1250 & 0 & $.6789 * *$ \\
\hline Bottom & .7950 & $1.0795 * *$ & .0564 & $.2975^{*}$ & 0 & $.6779 *$ \\
\hline Dark & .8141 & $1.2250 * *$ & .0674 & $.3749 *$ & 0 & $.6586 * *$ \\
\hline
\end{tabular}

*Significant $(F)$ simple main effects at $p<.05$.

${ }^{*}$ Significant $(F)$ simple main effects at $p<.01$. 
conditions were altered. This readily corresponds to observations on human beings with marginal vestibular dysfunction, who have difficulty in maintaining adequate orientation in the dark (Brown \& Hinshaw, 1949; Glorig \& Fowler, 1947).

The most sensitive measure of vestibular dysfunction appears to be the percentage of time spent underwater in that the control and experimental groups differed in all three lighting conditions. Additionally, both dark and bottom-lighting conditions appear to be sensitive indexes of marginal vestibular dysfunction because they reliably differentiated the swimming behavior of the two groups on all three measures: swim times, errors, and percentage of underwater time.

\section{GENERAL DISCUSSION}

Results from all four experiments confirm that sodium arsanilate (atoxyl) is ototoxic to rats, as it is to guinea pigs (Anniko \& Wersall, 1975, 1976, 1977).

Even though we have not attempted to identify that damage by histological means, the underlying assumption of these experiments is that sodium arsanilate injections induce vestibular damage. This assumption is supported by the work of Riccio et al. (1967), who produced histologically identified damage by intratympanic injections of streptomycin, and Anniko and Wersall (1975), who produced histologically identified damage by subcutaneous injections of sodium arsanilate. Furthermore, the contention that these behavioral deficits are due to vestibular dysfunction is supported by the fact that saline-injected rats do not show these deficits-either by subcutaneous or intratympanic injections.

Escape from the water maze was found to be a sensitive index of vestibular functioning. It was especially sensitive when vestibular damage was produced before the animal learned to escape from the water maze. At a dose of sodium arsanilate that had produced no discernible vestibular dysfunction in the rats in Experiment 1, sodium arsanilate did impair the acquisition of the escape response in the rats of Experiment 3. Furthermore, the rats from Experiment 3 that received two $40-\mathrm{mg} / \mathrm{kg}$ doses of sodium arsanilate before acquiring the escape response differed qualitatively from rats without dysfunction in that they swam more of the maze submerged. For these reasons, the most sensitive test of vestibular functioning would be to first swim the rat after drug administration, and the most sensitive index would be the percentage of time spent underwater. Normal animals seldom swam under the surface of the water, while rats that had marginal dysfunction had significant periods of underwater swimming throughout most of the sessions.

Lighting conditions also revealed vestibular dys- function, especially when the light came from the bottom of the maze or was functionally absent. It appears that rats increase their reliance on visual cues following damage to the vestibular system, and, by removing or giving contradictory visual cues, it was possible to reveal vestibular deficits that were previously concealed.

An unexpected finding was that sodium arsanilate has a differential effect upon two different strains of rats. Hawkins and Preston (1975) and Lindquist (1973) speculated that the effects of streptomycin and other ototoxic drugs were to destroy the dark secretory cells of the vestibular epithelium and that this destruction leads to a disruption of the microhomeostasis of the fluids in the inner ear and to a secondary destruction of the type I and II hair cells. Lindquist (1973) proposed that albino animals, which lack melanin in their inner ear structures (Wolff, 1931), would be more resistant to the action of these ototoxic agents than pigmented animals. However, in Experiment 1, just the opposite effect was found. The pigmented animals (Long-Evans rats) were much more resistant to the action of sodium arsanilate than albino animals (Wistar rats). The reasons for this are not clear. The lack of strain differences following intratympanic injections in Experiment 2 suggests that the differences are not due to differences in the sensitivities of the vestibular apparatus; rather, there would appear to be a systemic difference between the two strains of rats.

\section{REFERENCES}

Anniko, M., \& LJungqvist, A. The nephrotoxic effect of the ototoxic compound atoxyl. Acta Pathologica of Microbiologica Scandinavica Section A: Pathology, 1977, 85, 751-760.

Anniko, M., \& Wersall, J. Damage to the stria vascularis in the guinea pig by acute atoxyl intoxication. Acta OtoLaryngologica, 1975, 80, 167-179.

Anniko, M., \& Wersall, J. Afferent and efferent nerve terminal degeneration in the guinea pig cochlea following atoxyl administration. Acta Oto-Laryngologica, 1976, 82, 325-336.

AnNiko, M., \& Wersall, J. Experimentally (atoxyl) induced ampullar degeneration and damage to the maculae utriculi. Acta Oto-Laryngologica, 1977, 83, 429-440.

Brown, H. A., \& Hinshaw, H. C. The otologic effects of streptomycin therapy. Annals of Otology, Rhinology, and Laryngology, 1949, 58, 111-116.

Causse, R., Gendet, I., \& Vallanciian, B. Action vestibulaire de la streptomycine chez la souris. Comptes Rendus des Séances de la Société de Biologie, 1948, 142, 747-749.

Dichgans, J., Bizzi, E., Morasso, P., \& Tagliasco, V. Mechanisms underlying recovery of eye-head coordination following bilateral labyrinthectomy in monkeys. Experimental Brain Research, 1973, 18, 319-322.

Duvall, A. R., \& Wersall, J. Site of action of streptomycin upon inner ear sensory cells. Acta Oto-Laryngologica, 1964, 57, 581-598.

Fregly, A. R., \& Graybiel, A. Labyrinthine defects as shown by ataxia and caloric tests. Acta Oto-Laryngologica, 1970, 69, 216-222. 
Glorig, A., \& Fowler, E. P., JR. Tests for labyrinth function following streptomycin therapy. Annals of Otology, Rhinology, and Laryngology, 1947, 56, 379-394.

Gray, J., \& Lissman, H. W. The effects of labyrinthectomy on the coordination of limb movements in the toad. Journal of Experimental Biology, 1947, 24, 36-45.

Hawkins, J. E., Jr., Johnson, L. G., \& Aran, J. M. Comparative tests of gentamicin ototoxicity. Journal of Infectious Diseases, 1969, 119, 417-426.

Hawnins, J. E., Jr., \& LURIE, M. H. The ototoxicity of dihydrostreptomycin and neomycin in the cat. Annals of Otology, Rhinology, and Laryngology, 1953, 62, 1128-1148.

Hawkins, J. E., JR., \& Preston, R. E. Vestibular ototoxicity. In R. F. Naunton (Ed.), The vestibular system. New York: Academic Press, 1975.

HoRn, E., \& RAYER, B. Compensation of vestibular lesions in relation to development. Naturwissenschaften, 1978, 65, 441.

HoW ARD, I. P., \& TEM PLETON, W. B. Human spatial orientation. New York: Wiley, 1966.

Ig ARAshi, M. Squirrel monkey rail test. Acta Oto-Laryngologica, 1968, 66, 199-212.

Igarashi, M., Watanabe, T., \& Maxian, P. M. Dynamic equilibrium in squirrel monkeys after unilateral and bilateral labyrinthectomy. Acta Oto-Laryngologica, 1970, 69, 247-253.

JoHANSEN, J. Studies on the effect of arsacetin on the labyrinth. Proceedings of the Fifth International Congress of Otolaryngology, 1953, 579-585.

Jongkes, L. B. W., \& HuLK, J. The action of streptomycin on vestibular function. Acta Oto-Laryngologica, 1950, 38, 225-232.

KANDA, T., \& Ig ARASHI, M. Ultrastructural changes in vestibular sensory organs after viomycin sulfate intoxication. Acta OtoLaryngologica, 1969, 68, 474-488.
Lindquist, N. G. Accumulation of drugs on melanin. Acta Radiologica, Stockholm Supplement, 1973, 325, 54-61.

Molitor, H., Graessle, O. E., Kuna, S., Mushett, C. W., \& Silber, R. H. Some toxicological and pharmacological properties of streptomycin. Journal of Pharmacy and Experimental Therapeutics, 1946, 86, 151-173.

Northington, P. Syndrome of bilateral vestibular paralysis and its occurrence from streptomycin therapy. Archives of Otolaryngology, 1950, 52, 280-396.

PARKer, D. E. The vestibular apparatus. Scientific American, $1980,243,118-135$.

Pusakulich, R. L., \& Nielson, H. C. Cue use in state-dependent learning. Physiological Psychology, 1976, 4, 421-428.

Riccio, D., Igarashi, M., \& Eskin, A. Modification of vestibular sensitivity in the rat. Annals of Otology, Rhinology, and Laryngology, 1967, 76, 179-188.

Riopella, A. J., \& HubBard, D. G. Vestibular dysfunction and swimming in monkeys. Federation Proceedings, 1979, 38, 1310.

T'ANG, Y., \& Wu, C. F. The effects of unilateral labyrinthectomy in the albino rat. Chinese Journal of Physiology, 1936, 10, 571-598.

T'ANG, Y., \& Wu, C. F. The effects of bilateral labyrinthectomy in albino rats. Proceedings of the Chinese Physiological Society, 1937, 10, 33-34.

WATT, D. G. D. Responses of cats to sudden falls: An otolithoriginating reflex assisting landings. Journal of Neurophysiology, 1976, 39, 257-265.

WolfF, D. Melanin in the inner ear. Archives of Otolaryngology, $1931,14,195-211$.

(Manuscript received March 27, 1981; revision accepted for publication September 9, 1981.) 